\title{
The State of Benzene in TIP Slurry Using Nuclear Magnetic Resonance Measurements
}

by

L. O. Dworjanyn

Westinghouse Savannah River Company

Savannah River Site

Aiken, South Carolina 29808

\section{RECEIVED \\ JAN 151998 \\ OSTI}

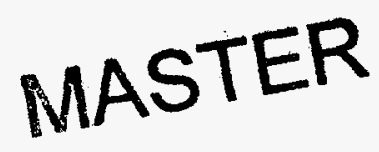

DOE Contract No. DE-AC09-96SR18500

This paper was prepared in connection with work done under the above contract number with the U. S.

Department of Energy. By acceptance of this paper, the publisher and/or recipient acknowledges the U. S. Government's right to retain a nonexclusive, royalty-free license in and to any copyright covering this paper, along with the right to reproduce and to authorize others to reproduce all or part of the copyrighted paper. 


\section{DISCLAIMER}

Portions of this document may be illegible electronic image products. Images are produced from the best available original document. 
Keywords: In-Tank Precipitation, ITP

Tetraphenylborate, TPB

Benzene Retention in TPB

Nuclear Magnetic Resonance,

NMR Microscopy

Slurry

Retention Period: Lifetime

November 14, 1997

TO: W. L. Tamosaitis

FROM: L. O. Dworjanyn
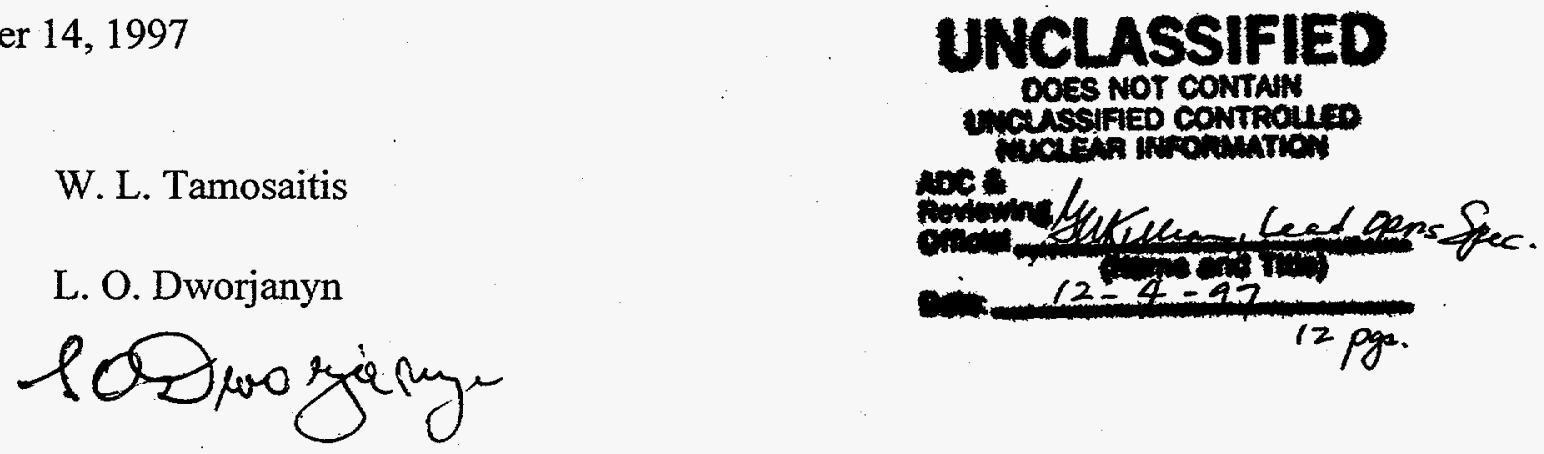

The State of Benzene in ITP Slurry Using

Nuclear Magnetic Resonance Measurements (U)

\section{INTRODUCTION}

Nuclear Magnetic Resonance (NMR) measurements on In-Tank Precipitation (ITP) simulated potassium tetraphenylborate (KTPB) slurries at Pacific Northwest National Laboratory have been completed. Most measurements were made on $4 \mathrm{wt} \%$ KTPB slurry in 4 to 5 molar sodium salt solution (Ref. 1). Liquid benzene was added volumetrically to the slurry in $25-\mathrm{mL}$ vials and agitated to create a suspension. Earlier tests using dyed benzene showed that benzene remains suspended permanently in the slurry and the only visible change is overall slurry settling. Gentle vial agitation restores the original suspension state.

To simulate in-situ uriformly dispersed benzene, benzene/KTPB samples were homogenized using a high speed rotor/stator biological homogenizer (Ref. 2). Photomicrographs using homogenized samples containing dyed benzene showed no residual benzene droplets and fairly uniform coloration of the KTPB solids structure (Ref. 2). 
All benzene concentration estimates are based on benzene addition since there is no available analytical method for benzene in slurry. Benzene losses could be significant, particularly at low concentrations and during homogenization.

\section{SUMMARY}

1. NMR imaging of the benzene distribution in nonhomogenized KTPB slurries show that benzene is retained in descrete droplets with diameters between 50 and 200 microns. Interogation of individual droplets using localized NMR spectroscopy confirmed that observed droplets were indeed pure benzene in agreement with earlier observations using dyed benzene (Ref. 1). Microscopic observations have also shown that the benzene droplets are coated with the hydrophobic KTPB particles which prevents droplets from coalescing (Ref. 1). NMR imaging and Spectroscopy show that with continued agitation, benzene is dispersed into smaller and smaller droplets which gradually fill with KTPB particles.

2. NMR Spectroscopy on well homogenized KTPB/benzene slurry samples show an equimolar distribution of KTPB and benzene. NMR Diffusion measurements show that the liquid benzene is present in a 2-dimensional surface layer, presumably coating individual KTPB particles. Diffusion measurements further show that diffusing benzene molecules can move over surprisingly large distances (e.g. $>80 \mu \mathrm{m}$ in $5 \mathrm{sec}$ ), implying a connected 3-dimensional network structure in which the benzene acts as a glue binding benzene wetted KTPB particles inside the salt solution. This is consistent with observed slurry flocculation and enhanced settling/separation as benzene concentration is increased (Ref. 1).

3. Previous work has shown that at higher benzene concentrations (equal volumes of KTPB and benzene, or 1:4 molar ratio) the benzene forms a continuum in which all available KTPB is taken up by the benzene (Ref. 1). This is evidenced by $\mathrm{KTPB} /$ benzene balls floating in clear salt solution. At still higher benzene concentrations, the balls become softer and more fluid.

4. At lower benzene concentrations between 500 and $5,000 \mathrm{ppm}$, no benzene could be detected using NMR Spectroscopic measurements performed on homogenized, $4 \mathrm{wt} \%$ slurry. Since overall detection sensitivity was shown to be high enough for detecting concentrations as low as $2000 \mathrm{ppm}$ in benzene saturated water standards, this data indicated that significant amounts of benzene was "immobilized" and tightly bound to surfaces of KTPB particles. In such a non-liquid state, the benzene was therefore not observable using liquid state NMR techniques which rely on the rotational freedom of liquid molecules. Actual concentration of immobilized benzene could not be confirmed, however, due to uncertainty in sample preparation and lack of a benzene in slurry analytical method. These findings are consistent with dyed benzene observations which showed no color development below 3,000 ppm benzene (Ref. 1). 
5. Attempts to measure the state of in-situ generated benzene in DEMO samples (Refs. 3 and 4) was not successful because of extreme line broadening by metallic constituents in the DEMO formulation. Attempts to measure benzene in a simpler non-metallic slurry in a larger, $1 \mathrm{in}$. diameter column also failed due to high conductivity of the salt solution which prevented radio frequency field penetration through the larger sample.

\section{CONCLUSIONS}

- NMR measurements provide a unique method for characterizing the state of benzene in KTPB slurries, allowing

(i) three dimensional visualization of benzene droplets and their spatial distribution,

(ii) benzene concentration measurements in the slurry and observed microstructures,

(iii) characterization of benzene retaining microstructures and their connectivity by NMR diffusion measurement, and

(iv) estimates of "immobilized" benzene by difference from known concentration and measured benzene levels.

- The state of in-situ benzene could be examined by utilizing metal free simulants. Observation of in-situ benzene generation would have to be restricted to smaller diameter columns, or KTPB slurry in water. The state of benzene in the current homogenized benzene/KTPB slurry is probably a close approximation to the state of in-situ benzene at 10,000 to $15,000 \mathrm{ppm}$. At lower benzene concentrations the in-situ benzene may be distributed more uniformly than is possible with homogenization since the benzene would be deposited atom by atom, rather than from liquid concentrations.

\section{REFERENCES}

1. L. O. Dworjanyn, "Benzene Retention in KTPB Slurry - Status Report (U)", WSRCRP-97-217, Rev. 0, March 26, 1997

2. L. O. Dworjanyn, "Benzene Release - Status Report (U)", WSRC-RP-97-903, Rev. 0, November 4, 1997.

3. J. C. Marek, "Task Technical Plan for Pilot-Scale Benzene Retention and Release Demonstration" (U) DEMO Tests, SRT-PTD-96-0090, December 19, 1996.

4. J. C. Marek and W. B. Van Pelt, "Pilot-Scaie Benzene Retention and Release Demonstration (U)", DEMO Tests, SRT-TR-97-00360, Rev. 0, November 1997.

5. L. O. Dworjanyn, WSRC-NB-94-134. 


\section{APPROVALS}

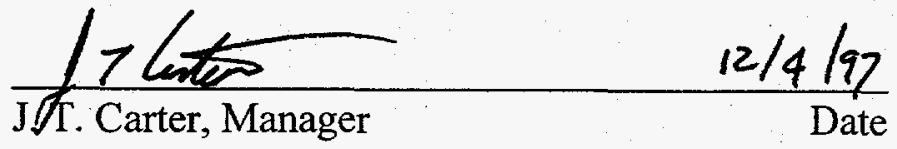

ITP Flow Sheet Task Team

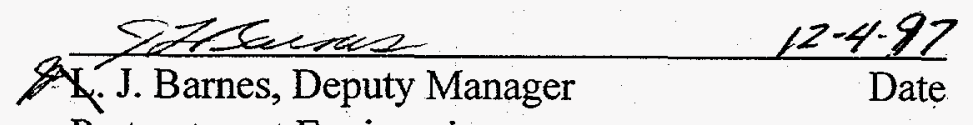

Pretreatment Engineering

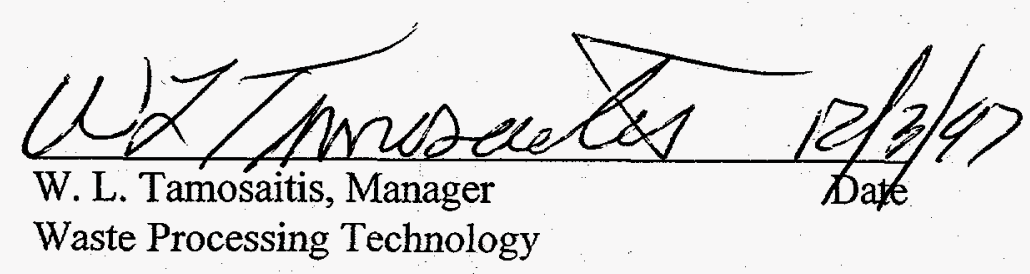

D:lapplbretımrilminard.doc 


\title{
NMR Microscopy of Savannah River Tank Waste Simulants
}

\author{
Kevin R. Minard and Robert A. Wind \\ Pacific Northwest National Laboratory, P.O. Box 999, Richland, WA 99352
}

\section{Summary and Introduction}

At the Savannah River Site, an In-Tank Precipitation (ITP) process, designed to remove soluble radioactive cesium-137, employs sodium tetraphenylborate (NaTPB) as a precipitation reagent. During initial tests, it was found that this process unexpectedly generated large concentrations of benzene, which was retained in the tank waste slurry, which mainly consists of potassium tetraphenylborate (KTPB). As a result, all ITP operations were shut down and a systematic effort has been undertaken to gain a better understanding of the factors controlling benzene generation, retention, and release in ITP slurries [1].

In this report, results are presented of a magnetic resonance (MR) microscopy study to characterize the microscopic environment of benzene in simulated ITP slurries. Results from MR microscopic imaging and diffusion experiments are first discussed. These tests were carried out on a slurry, consisting of water, $4 \mathrm{wt} \%$ potassium tetraphenylborate, $5 \mathrm{~mol} / \mathrm{L} \mathrm{Na}$ salts, and $5 \mathrm{vol} \%$ benzene. Three-dimensional images of the benzene distribution in $1.5 \mathrm{~mm}^{3}$ samples were acquired with spatial resolutions as high as $10 \times 10 \times 10 \mu \mathrm{m}^{3}$. It was found that liquid benzene was retained in pure droplets with diameters between 50 and $200 \mu \mathrm{m}$, coated with KTPB. It was also observed that when the samples were shaken, the droplets dispersed, and the KTPB penetrated the droplets. After intense shaking, relatively large KTPB/benzene agglomerates formed in which the KTPB and benzene become closely associated, and the 
benzene can diffuse over relatively large distances (at least a few hundred $\mu \mathrm{m}$ ), but with a limited diffusion coefficient. These results were confirmed by bulk restricted diffusion measurements.

Results of bulk benzene concentration measurements in simulated slurries are also presented. It was found that in strongly agitated, homogenized slurries the measured benzene concentration is considerably less than the actual amount of added benzene, and even becomes zero if sufficient KTPB is added. In these samples a major part or all of the benzene is apparently tightly bound to the KTPB, making it NMR 'invisible'. It was determined that the ratio of KTPB and bound benzene molecules is approximately 1:1.

\section{Experimental}

\subsection{Samples}

The experiments were performed on simulated non-radioactive tank waste slurries. The slurry composition was based on various tests performed to characterize the tank waste, leaving out intermediate decomposition products or soluble metals. The slurry used for the imaging and diffusion experiments consists of water, approximately $5 \mathrm{~mol} / \mathrm{L}$ of various dissolved Na salts, rendering the $\mathrm{pH}$ to $13-14,4 \mathrm{wt} \%$ insoluble $\mathrm{KTPB}$, and $50 \mathrm{~g} / \mathrm{L}$ benzene, injected into the slurry. The benzene was dispersed by gently shaking the sampie by hand. This sample will be referred to as the non-agitated slurry. In order to investigate the effects of more pronounced shaking, two types of agitation were applied: (i) A horizontal half-filled vial was shaken slowly back and-forth for about $1 / 2$ hour; (ii) The slurry was put in a blender for a few minutes. These procedures are referred to as gentle and strong agitation, respectively. The benzene concentration measurements were carried out on a benzenesaturated water standard containing 2013 ppm benzene, a benzene-saturated saline standard containing 300 ppm benzene, a strongly agitated, homogenized slurry containing $4.2 w t \%$ KTPB and injected with $4500 \mathrm{ppm}$ benzene, and a homogenized slurry containing $10 \mathrm{wt} \%$ KTPB and 4970 ppm benzene. 


\subsection{Methods}

\subsubsection{MR microscopy and diffusion experiments}

Proton MR microscopy experiments were performed in a $89 \mathrm{~mm}$ i.d. vertical bore magnet operating at 11.7 Tesla, corresponding to a proton Larmor frequency of $500 \mathrm{MHz}$, using a Varian UNITYplus imaging/spectroscopy console, and a microimaging probe manufactured by D.G. Cory and coworkers at the Massachusetts Institute of Technology (MIT) as part of a collaborative project between PNNL and MIT, and funded by DOE's measurement science's program, to develop MR microscopy in fields up to $21 \mathrm{~T}$. The probe is capable of generating gradients up to $10 \mathrm{~T} / \mathrm{m}$.

The measurements were performed at room temperature on samples contained in sealed glass tubes with an i.d. of $1.3 \mathrm{~mm}$, mounted in a NMR coil of both an i.d. and a length of 1.7 $\mathrm{mm}$. Three-dimensional (3D) images were acquired using a spin-echo imaging sequence that employed standard phase and frequency encoding methods for sampling $\mathrm{k}$-space. With isotropic resolutions between 10 and 25 microns, the point spread function was dominated by $\mathrm{T}_{2}$-losses rather than diffusion-losses, and therefore data was collected using a $\mathrm{T}_{2}$-optimal acquisition bandwidth. Water suppression was achieved by using an inversion-recovery preparation period that employed a hard pulse. With gross differences in $\mathrm{T}_{1}$-relaxation rates between water and benzene $\left(\mathrm{T}_{1}\left(\mathrm{C}_{6} \mathrm{H}_{6}\right) \sim 7.0 \mathrm{sec}\right.$ and $\left.\mathrm{T}_{1}\left(\mathrm{H}_{2} \mathrm{O}\right) \sim 1.0 \mathrm{sec}\right)$, the water signal was easily nulled by an appropriate choice of the inversion time. Additional water suppression was achieved by using a benzene-selective refocusing pulse for forming the spin-echo. Together with the hard inversion pulse and appropriately placed crusher gradients, water was typically suppressed more than 200 fold during benzene-only 3D data acquisitions. Moreover, by using a hard inversion pulse, even water near air bubbles was adequately suppressed despite large frequency offsets from susceptibility effects. If only frequency selective methods for water suppression were used, such water tended to contaminate benzene-only images.

In addition to 3D images, two-dimensional multislice (2D) benzene-only and water-only images were acquired. For the benzene-only images, a șequence was used that employed the water suppression scheme similar to that already described above. For the water-only 
imaging, adequate benzene suppression was obtained by omitting the inversion sequence, and by simply using a short recycle delay time of $1 \mathrm{sec}$.

To detect and quantify possible benzene-containing voids below the spatial resolution of acquired images, pulsed-field gradient diffusion measurements were performed. These were conducted using a hybrid of the original 13 -interval Cotts sequence that was previously described in detail by others [3]. Briefly, this sequence employed a stimulated echo, which allowed molecular motion to be probed over time scales larger than 5 seconds since the benzene $T_{1}$ was sufficiently long. To eliminate the effects of background gradients, the sequence employed additional refocusing of RF pulses and gradient pulses of alternating sign. In addition, an eddy-current stabilization period prior to each data acquisition ensured that eddy currents induced in the 4.2 molar saline solution would be in a steady state during actual data acquisition. As a result, eddy-currents merely distorted the final shape of the applied gradient waveform and experimental results were easily corrected via calibration with appropriate standards. In the strongly agitated sample the effects of eddy currents could be ignored completely since little water was actually present in the sample region. This was confirmed using identical samples that had been washed repeatedly with distilled water to remove conducting sodium ions. In the other samples the effects of eddy-currents on the measured water diffusion could be used as an internal calibration for correcting the benzenediffusion data. For all three samples a series of echo-attenuation measurements were carried out in which the mixing time was arrayed, keeping all other paraneters constant. From these measurements the apparent diffusion coefficient was determined, and plots were generated for this coefficient as a function of the diffusion time.

\subsubsection{Concentration measurements}

Localized spectroscopy was performed at $300 \mathrm{MHz}$ using a magnetic resonance imaging probe, manufactured by Doty Scientific, Inc., which has a large enough bore to accommodate a $40 \mathrm{~mm}$ diameter sample. Benzene concentrations were measured by comparing the intensity of the benzene resonance with that of water in any particular region. Concentration data were acquired with intact vials prepared at Savannah River, i.e. entire sealed sample 
vials were put inside the imaging system. This was done to assure that all the added benzene was still present in the sample.

\section{Results and Discussion}

\subsection{MR microscopy and diffusion}

Fig. 1 shows water-only, benzene-only, and composite 2D images of a slice through the non-agitated tank waste simulant. The composite image was obtained by simply superimposing the water-only and benzene-only images. It follows that in this sample the benzene is present in isolated droplets. It can also be seen from the composite image that the droplets are surrounded by $10-20 \mu \mathrm{m}$ thick dark layers, presumably consisting of the solid KTPB.

Figure 1.

2D Images of the water distribution (A), the benzene distribution (B), and the composite image (C) of a region in the non-agitated sample. Slice thickness $=150 \mu \mathrm{m}, \mathrm{FOV}=1.3 \times 1.3 \mathrm{~mm}^{2}$, planar resolution $=10 \times 10 \mu \mathrm{m}^{2}$. $\mathrm{TE}=3.3 \mathrm{msec}, \mathrm{TR}=1.0 \mathrm{sec}(\mathrm{A})$ and $20 \mathrm{sec}(\mathrm{B})$.

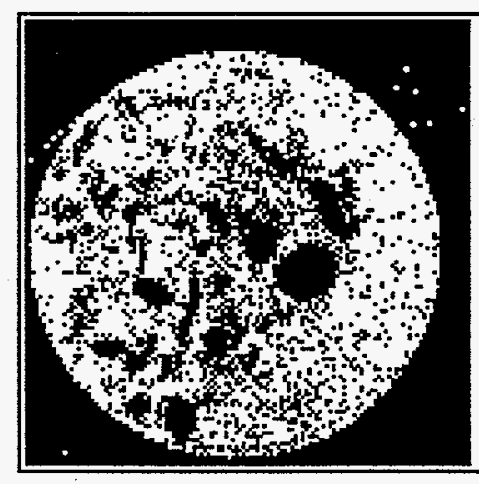

A

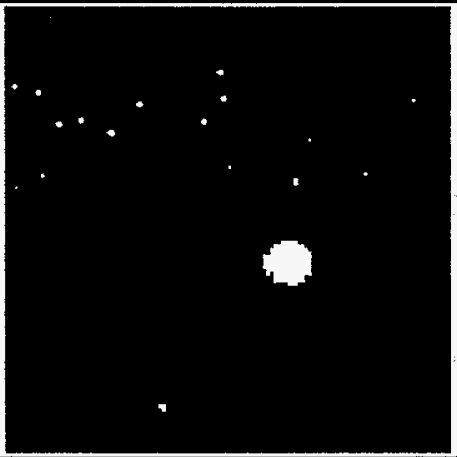

B

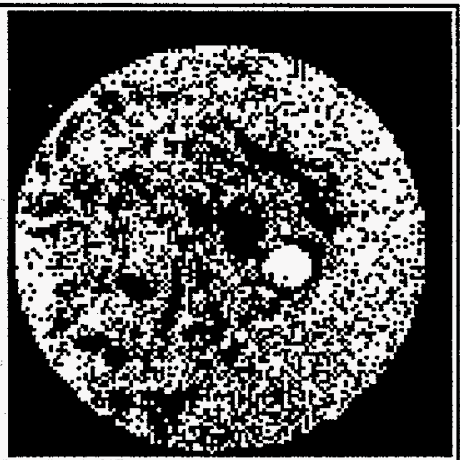

C 
Fig. 2 shows the three-dimensional distribution of the benzene in the three samples.

Fig. 2A shows the result for the non-agitated waste simulant, confirming the presence of benzene droplets with diameters of 50-200 $\mu \mathrm{m}$. Comparison of the benzene signal-to-noise ratio inside of the droplets with that of identical images of a bulk benzene standard indicated that the droplets consist of pure benzene. Figures $2 \mathrm{~B}$ and $2 \mathrm{C}$ display the three-dimensional benzene distribution in the gently and strongly shaken samples.

\section{Figure 2.}

Three-dimensional images of the benzene distribution in the non-agitated (A), the gently agitated $(B)$, and the strongly agitated $(C)$ tank waste simulant. $F O V=1.3 \times 1.3 \times 1.3 \mathrm{~mm}^{3}$, spatial resolution $=10 \times 10 \times 10 \mu \mathrm{m}^{3}$ (A), $20 \times 20 \times 20 \mu \mathrm{m}^{3}$ (B), and $25 \times 25 \times 25 \mu \mathrm{m}^{3}$ (C). TE $=9.1 \mathrm{msec}, \mathrm{TR}=5 \mathrm{sec}, \mathrm{NA}=2,64 \times 64$ phaseencoding steps. The bars represent a distance of $200 \mu \mathrm{m}$.

A
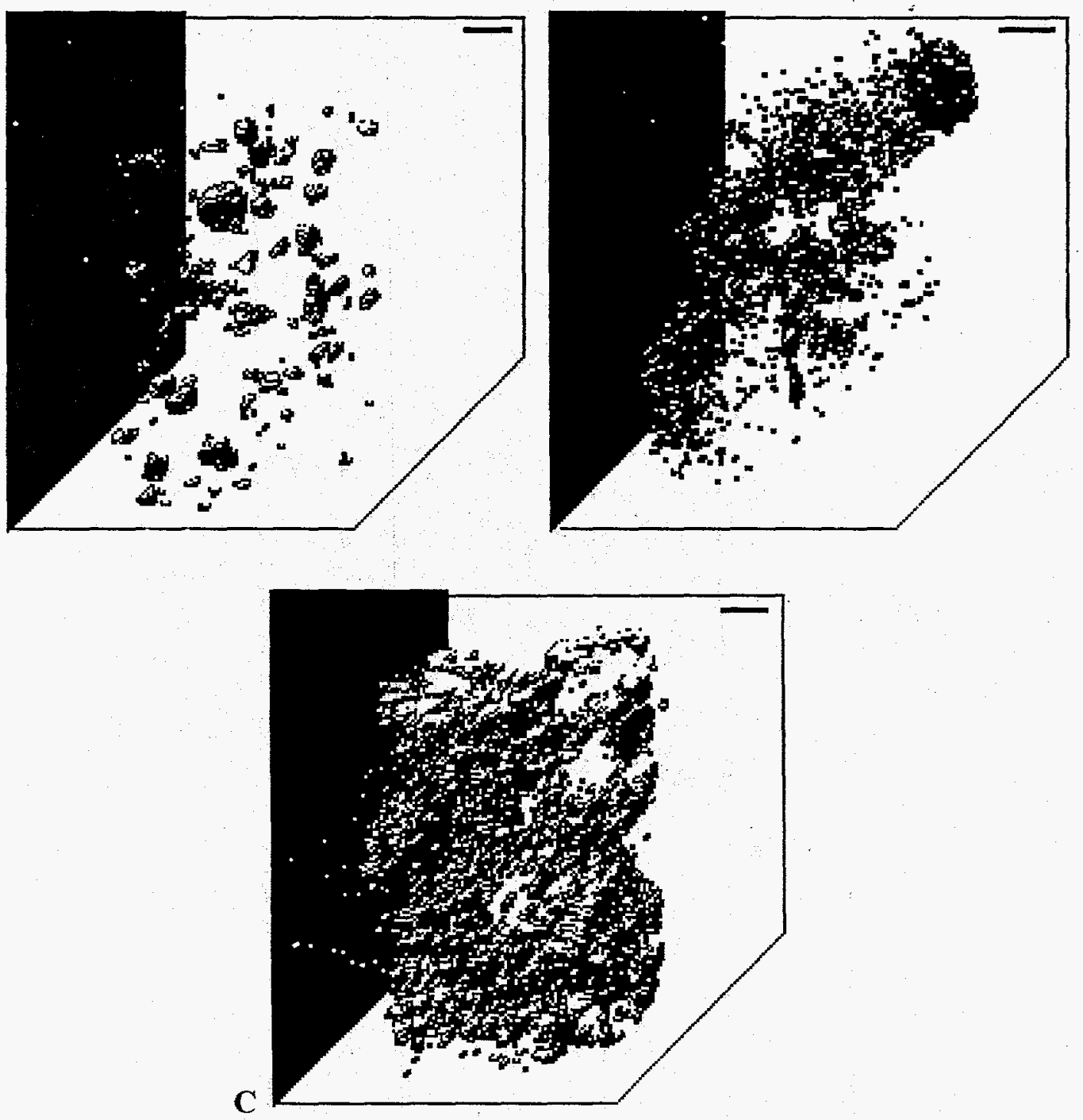
It follows that the agitation has a profound impact on the way the benzene is dispersed: after gentle agitation part of the benzene is distributed in much smaller droplets, which become a compact agglomerate after intense agitation. It was also found that agitation decreases the benzene concentration in the benzene-containing globules from $100 \%$ in the non-agitated sample to $40-70 \%$ in the gently agitated sample to $20-50 \%$ in the strongly agitated sample. As no water was detected in these globules, this means that after agitation the individual droplets become filled with KTPB particles, forming stable agglomerates with the benzene. We conclude that in the agitated samples benzene-containing microstructures occur with sizes were well below the spatial resolution of the images.

The imaging results are confirmed by the restricted diffusion measurements. In Figure 3

\section{Figure 3.}

Normalized apparent diffusion coefficients measured as a function of diffusion time $(\Delta)$ in bulk benzene $(\boldsymbol{Q})$, and in the non-agitated ( $\boldsymbol{X})$, gently agitated ( $)$, and strongly agitated (I) tank waste simulant. The diffusion coefficient of free benzene, $D_{0}$, was measured to be: $D_{0}=2.2 \times 10^{-9} \mathrm{~m}^{2} \mathrm{~s}^{-1}$, in accordance with the literature (ref. [2] p. 165).

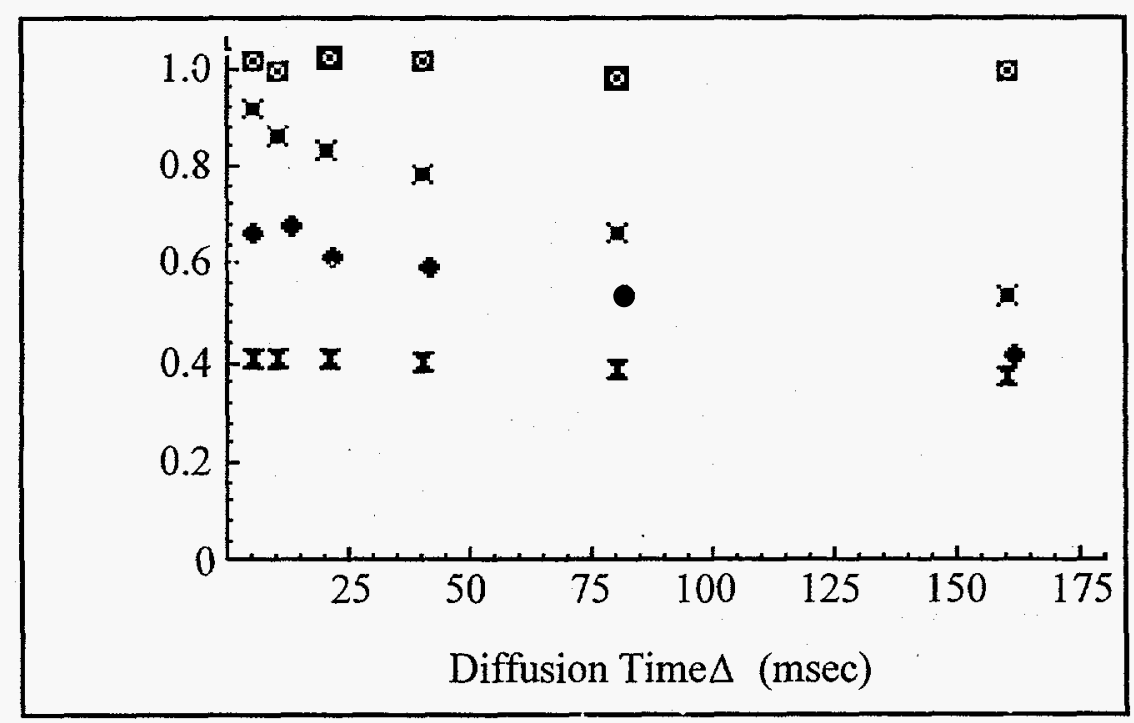

the apparent diffusion coefficients, norrnalized by the diffusion coefficient of free benzene, $\mathrm{D} / \mathrm{D}_{\mathrm{o}}$, and plotted as a function of the diffusion time $(\Delta)$, are shown for the three samples. In the non-agitated sample, the diffusion coefficient gradually decreases with time, indicative of 
restricted motion. Because a complete analysis of the results is difficult to perform in this heterogeneous sample, a simpler approach was used, in which only the short-time and the long-time behavior of the diffusion coefficient was considered. From the initial slope of the curve $\mathrm{D} / \mathrm{D}_{\mathrm{o}}$ versus $\Delta$, the average diameter (d) of the droplets governing this time-dependent behavior can be calculated [3,4]. Assuming spherical droplets, the result is: $d=65 \mu \mathrm{m}$. At long diffusion times, the apparent diffusion coefficient (D) approaches the limit: $D=d^{2}(20 \Delta)$ (ref. [2] p. 374). ). For the non-agitated sample D was measured for long diffusion times as well, and $0.07 \mathrm{D}_{\mathrm{o}}$ was obtained for a diffusion time of $6 \mathrm{sec}$, corresponding to $\mathrm{d}=140 \mu \mathrm{m}$. Hence, in the non-agitated sample, the droplet sizes following from the restricted diffusion are similar to the ones observed in the images.

It follows from Figure 3 that the benzene mobility is significantly reduced in the agitated samples. We first consider the strongly agitated sample. It is found that even for the shortest diffusion times the apparent diffusion coefficient is reduced to a value $0.4 \mathrm{D}_{0}$, and that this value hardly changes with increasing diffusion times (we found this result to be true even for diffusion times as long as $5 \mathrm{sec}$ ). Two scenarios are possible to explain these results [5]: (i) The benzene is present in small voids with diameters of a few $\mu \mathrm{m}$ (causing the initial fast, undetected, decrease in D), which are interconnected, thereby allowing the benzene to diffuse over distances much larger than the void size (this explains the long-time behavior); (ii) The diffusion coefficient is reduced because the benzene is diffusing in thin layers bound to KTPB surfaces, but the total surface area of the layers is large, allowing the benzene molecules to move over large distances, at least several hundred $\mu \mathrm{m}$. Taking into account the results of the concentration measurements, discussed below, where it was found that large parts of the benzene are strongly bound to the KTPB, the second explanation is more likely correct. However, in either case the restricted mobility of benzene must result from an intimate mixture of the benzene with the KTPB, which is again in accordance with the imaging results. Note that in an agitated sample containing less benzene $(15 \mathrm{~g} / \mathrm{L})$, the diffusion coefficient is reduced to $0.09 \mathrm{D}_{\mathrm{o}}$. Hence in this sample the diffusion is even further restricted, presumably due to the presence of thinner layers in this sample and/or increased exchange interactions between mobile and bound benzene). Finally, it follows from Figure 3 that the diffusion curve for the gently agitated sample is an intermediate case between those 
of the non-agitated and strongly agitated samples, indicating that larger droplets of $\mathrm{m} 7$ ore or less pure benzene and benzene/KTPB agglomerates are both present simultaneously.

\subsection{The benzene concentration}

We shall consider the results in the various samples separately.

- Benzene-Saturated Water Standard $\left(\left[\mathrm{Na}^{+}\right]=\mathbf{0}\right)$. Water and benzene resonances were observed with localized spectroscopy by selecting a region of interest (ROI) inside the middle of the sample vial. The dimensions of the ROI were $8.63 \mathrm{~mm} \times 8.77 \mathrm{~mm} \times$ $10 \mathrm{~mm}$. Analysis of acquired spectra indicated a local benzene concentration of 1843 ppm. This is comparable to, although lower than, the $2013 \mathrm{ppm}$ expected in water free of sodium salts.

- Benzene-Saturated Saline Standard $\left(\left[\mathrm{Na}^{+}\right]=4.2 \mathrm{Molar}\right)$. Several attempts were made to detect benzene resonances in this sample; however, results could not be confidently interpreted because acquired spectra were plagued by small baseline distortions having the same magnitude as the expected benzene signals. This prevented rigorous measurement and interpretation of results would be purely speculative at this time without additional experiments. The benzene concentration in this sample was expected to be around $300 \mathrm{ppm}$; these findings indicate that the benzene detection limit for the experimental setup described is somewhere between $300 \mathrm{ppm}$ and $2000 \mathrm{ppm}$.

- Homogenized Sample N4 (4 wt \% KTPB slurry in 4.2 Molar saline solution spiked with $4500 \mathrm{ppm} \mathrm{C}_{6} \mathrm{H}_{6}$ ). Sample N4 consisted of two distinct regions - both of which could be clearly distinguished in MR images (see Figure 4). The top of the sample consisted of slurry yhat made up about half of the total sample volume. In turn, the slurry floated on clear saline solution. Benzene concentrations were measured in both ROI's shown in figure 4. However, as in the Benzene-Saturated Saline Standard, benzene concentrations were too low to be confidently interpreted in region 1 . 
Figure 4.

Two-Dimensional MR image showing a $1 \mathrm{~mm}$ thick cross-section of sample N4. Planar resolution is $117 \mathrm{x}$ 117 squared microns.

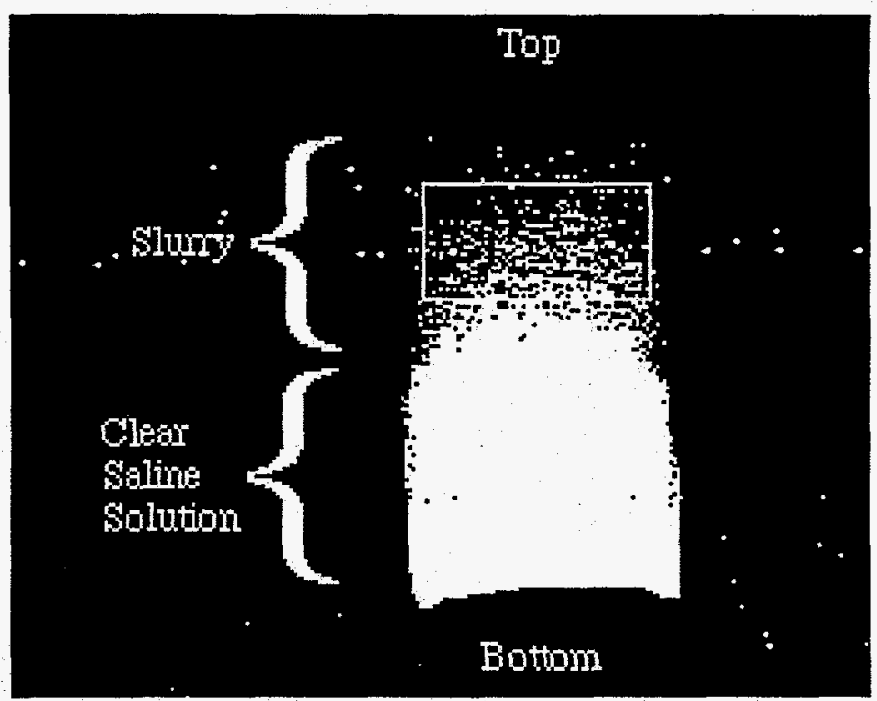

This is not surprising since benzene concentrations in the clear saline were expected to be around the saturation level $(300 \mathrm{ppm})$ for $4.2 \mathrm{Molar}$ saline solution. In the slurry layer, only $1670 \mathrm{ppm}$ of benzene was measured. Because all the solids were contained in half the total sample volume, a benzene concentration of $9000 \mathrm{ppm}$ was expected in this region. The large difference between the calculated and observed benzene concentration in the homogenized sample is attributed to the portion of the benzene tightly bound to the surfaces of the KTPB solids after being homogenized. In this state, a large fraction of the benzene is no longer observable using liquid state NMR measurements. Using the concentration of KTPB and the benzene given above, it can easily be calculated that $1 \mathrm{wt} \%$ KTPB binds about $1800 \mathrm{ppm}$ benzene, which means that the molar ratio of KTPB and bound benzene is approximately $1: 1$, assuming same specific density for the KTPB and the benzene. We also found in this sample that the chemical shift of the observed mobile benzene was about $6.5 \mathrm{ppm}$, which is considerably lower than the $7.2 \mathrm{ppm}$ of the benzene line measured in the benzene-saturated water. This means that the electronic shielding of the benzene protons in sample N4 is increased, which may be a result of increased stacking of the benzene molecules around the KTPB particles. 
- Homogenized Sample O4 (10 wt \% KTPB slurry in 4.2 Molar saline solution spiked with $4970 \mathrm{ppm} \mathrm{C}_{6} \mathrm{H}_{6}$ ). Unlike the samples already described, $\mathrm{O} 4$ was measured in an imaging probe too small to accommodate the entire vial. A small sample of $\mathrm{O} 4$ was sealed in a smaller $5 \mathrm{~mm}$-diameter vial after $\mathrm{O} 4$ was briefly shaken to redistribute the slurry uniformly throughout. Interestingly, no benzene was observable. Considering the results found in sample N4 made with only $4 \mathrm{wt} \%$ slurry, this finding was not surprising. In this context, one may conclude that $4 \mathrm{wt} \%$ slurry is enough to adsorb roughly 3500 ppm of benzene on its surfaces and that this amount presumably increases linearly with available surface area. Consequently, $10 \mathrm{wt} \%$ slurry is likely to adsorb more than 8700 ppm of benzene, which is well above the amount actually present.

\section{Conclusions and final remarks}

Based on the MR studies discussed above, the following picture emerges regarding the benzene retention in the simulated tank waste slurries: With minimal sample agitation the benzene is retained in the KTPB in the form of pure isolated benzene droplets with sizes of 50-200 microns. The droplets are coated by the hydrophobic KTPB, which stabilizes them in the slurry. When the slurry is shaken, the benzene is dispersed into small droplets, and become partialiy filled with KTPB. With continued agitation large three-dimensional $\mathrm{KTPB} /$ benzene agglomerates are formed in which each KTPB molecule binds approximately one benzene molecule. The remainder of the benzene is present in thin liquid layers around the KTPB, and allowed to diffuse over large distances (but with reduced diffusion coefficient) in the three-dimensional KTPB/benzene network.

Finally, we performed initial experiments to investigate whether MR microscopy could also be used to follow the in situ generation and retention of benzene in model columns of tank waste simulants. To this end we performed $300 \mathrm{MHz}$ MRI experiments in a three centimeter-diameter, foot-long stack of a slurry containing 4 wt \% KTPB, a 4.2 Molar saline solution, and injected with $\sim 2500 \mathrm{ppm}$ benzene. We found that due to the large resistive losses in this conductive sample the NMR coil no longer worked properly and that the RF 
field could penetrate only into the outer part of the sample. In principle, this problem could be overcome by reducing the sample diameter and/or its conductivity by eliminating the sodium salts, but whether in such a sample still can be regarded as a proper model for in situ benzene generation is unknown. We also investigated a smaller sample of a tank waste simulant which has been used at SRTC for in situ experiments, and we found that besides the RF penetration problems another problem arose: the water and benzene lines were severely broadened due to the presence of the metal traces present in this sample, which are responsible for the catalytic decomposition of excess NaTPB, generating the benzene. This line broadening will make it much more difficult to perform benzene-only experiments. Although more investigations are needed to evaluate the viability of MR microscopy as a tool to study in situ benzene formation, we tentatively conclude that the chances of success are not very high.

\section{References}

1. L.O. Dworjanyn, "Benzene Retention in TPB Slurry", Status Report, WSRC-RP-97-217, March 26, 1997.

2. P.T. Callaghan, Principles of Nuclear Magnetic Resonance Microscopy, Clarendon Press, Oxford, 1993.

3. E.J. Fordham, S.J. Gibbs, and L.D. Hall, Magn, Reson. Imaging 12 (1994) 279.

4. P.P. Mitra, P.N. Sen, and L.M. Schwartz, Phys. Rev. B 47 (1993) 8565.

5. P.T. Callaghan, K.W. Kolley, and R.S. Humphrey, J. of Coll. and Interf. Sci. 93 (1983) 521.

D:lapplbretlmrilnmrfinal.dot 


\title{
Distribution:
}

\author{
Aberra, G. A., 704-S \\ Andringa, K., 773-41A \\ Barnes, J. I., 704-S \\ Barnes, M. J., 773-A \\ Britt, T. E., 730-2B \\ Carter, J. T., 704-25S \\ Cauthen, G. I., 241-119H \\ Clark, W. C., 704-56H \\ Cloessner, P., 773-A \\ Crawford, C. L., 773-41A \\ Doughty, D. E., 704-56H \\ Eberlein, S. J., 704-56H \\ Eibling, R. E., 704-T \\ Elder, H. H. , 704-S \\ Fink, S. D., 773-A \\ Fowler, J. R., 704-Z \\ Griffin, J. C., 773-A \\ Hitchler, M. J., 730-2B \\ Hobbs, D. T. 773-A \\ Holtzscheiter, E. W., 773-A \\ Hsu, C. W. , 773-A \\ Hyder, M. L., 773-A \\ Jacobs, R. A., 704-T \\ Johnson, M. D. , 704-56H \\ keefer, M. T., 704-56H \\ Landon, L. F., 704-1T \\ Lewis, B. L., 703-H \\ Lex, T. J., 719-4A \\ Lowe, P. E., 773-41A \\ McCabe, D. J.; 773-43A
}

Melton, W. L., 241-154H

Menna, J. D., 730-2B

Miller, M. S., 704-56H

Montini, M. J., $704-56 \mathrm{H}$

Morin, J. P., 719-4A

Nash, C. A., 773-42A

Nelson, L. M. , 773-43A

Norkus, J. K., 730-2B

Papouchado, L. M., 773-A

Piccolo, S. F., 704-56H

peterson, R. A., 773-A

Poirier, M. R., 679-T

Randall, C. T., 704-T

Rutland, P. I., 241-152H

Satterfield, R. M., 719-4A

Suggs, P. C., 703-H

Swingle, R. F., 773-A

Tamosaitis, W. L., 773-A

Taylor, G. A., 703-H

Thomas, J. K., 730-2B

Van Pelt, W. B., 679-T

Walker, D. D., 773-A

Walker, W. C., 704-56A

Wiggins, A. W., 241-84H

wooten, I. A., 730-4B

Wright, G. T., 773-A

WPT-LWP Files,

c/o A. Patterson 773-A

TIM (4), 703-43A

ITP Library, c/0 A. Lemay, 241-121H 